\title{
Measles and stroke show why healthcare must innovate
}

\author{
Trevor Jackson deputy editor, BMJ
}

\begin{abstract}
"The question society has to answer is whether it is ethically acceptable to tolerate any serious complication, or death, from measles when an effective vaccine is available." So say public health specialists Felix Greaves and Liam Donaldson in their editorial reflecting on the recent epidemic of measles in south Wales and the prospect of large outbreaks in England (doi:10. 1136/bmj.f2793). With large cohorts of children and teenagers unvaccinated against measles, mumps, and rubella, health systems have been playing catch up as measles cases soar. Greaves and Donaldson turn the spotlight on the public health sector as it undergoes fundamental change.
\end{abstract}

"In a public health emergency, which is what the current measles threat is, it is vital that the response is well coordinated," they say. But strategic health authorities and primary care trusts that have been key in previous crises have been "devolved and swept away" and public health teams are scattered across local authorities. While Public Health England is charged with protecting the population's health, "resources for immunisation are with NHS England, an entity devoid of public health expertise at board level," say Greaves and Donaldson.

They are also concerned that if England fails to act resolutely, it will set a poor example to other countries, given the UK's history of calling for better vaccination in low and middle income countries. "More dynamism and innovation as well as good organisation is needed," they say.

From communicable to non-communicable diseases, and another call for innovation. Paul Corrigan and colleagues say that the pandemic of chronic diseases threatens the sustainability of health systems worldwide (doi:10.1136/bmj.f1699). The main reason is the escalating costs of looking after people with multiple chronic conditions such as diabetes and asthma. Corrigan and colleagues look at seven innovative approaches to reducing the burden of such diseases, including widespread uptake of the polypill (containing aspirin, a statin, and folic acid), an idea that was launched in the $B M J$ a decade ago ( $B M J$ 2003;326:1427). The polypill, which is currently undergoing trials for primary prevention, "could promote the sustainability of health systems by reducing the burden from stroke and myocardial infarction," they say. They acknowledge that drug companies might be resistant to something that could undercut markets, and that public health professionals may regard the pill as "an alternative rather than a supplement to a healthy lifestyle." But they say, "If as some studies suggest, half of heart attacks and strokes could be prevented, the savings could be enormous."

Pills for modern ills come under scrutiny elsewhere in this week's BMJ. A paper by Douglas and colleagues finds an association between orlistat, the only prescription drug available to treat obesity, and abnormalities in liver function (doi:10.1136/ bmj.f1936). But in an accompanying editorial, John Wilding concludes that orlistat remains useful for the treatment of obesity, "with an overall positive benefit-risk profile" (doi:10. 1136/bmj.f2777). And in his weekly column, Des Spence takes issue with the drug model of type 2 diabetes, "a modern plague largely brought on by lifestyle" (doi:10.1136/bmj.f2695). "The therapeutic approach in diabetes is upside down," he says.

Cite this as: BMJ 2013;346:f2819

๑ BMJ Publishing Group Ltd 2013 